\title{
The Influence of Capital Market Operations on the Nigeria Economic Growth (1990-2017)
}

\author{
Prof. Adeghe Ralph ${ }^{\mathrm{a}}$, Dr. Sunday Aguwamba ${ }^{\mathrm{a}}$, Abu Omoghosa James, \\ *projectgalore@yahoo.com \\ ${ }^{a}$ Department of Banking and Finance, Igbinedion University,Okada, Nigeria \\ ${ }^{b}$ Department of Banking and Finance, Edo State Polytechnic, Usen, Nigeria
}

\begin{abstract}
This study investigated the influence of capital market operations on the Nigeria economic growth, over the period of 1990 to 2017 and to carefully determine the causal relationship if any between Gross domestic product, Market capitalization, Volume of stock traded, value of stock traded, Turnover ratio and number of listed securities. This study made use of quantitative secondary data from the Nigeria stock Exchange, National Bureau of Statistics and the Central Bank of Nigeria (CBN) statistical bulletin (2017). The study employed descriptive statistics, Ordinary least square techniques, the Augmented Dickey-Fuller (ADF) unit root test, co-integration test and error correction model (ECM) to determine the relationship among the dependent and independent variables. Empirical results from the study revealed the intercept appeared with a positive result of 794981.5. Market capitalization showed a positive relationship with a value of 3532.394. Volume of stock traded was 179115.0. Value of stock traded was 148028.0. Number of listed securities has a positive value of 361550.6. Turnover ratio was 10911929. This in essence means that the influence of the capital market on economic growth is strong and significant. Another major outcome of the study is that a unit increase in market capitalization, volume of stock traded, value of stock traded, number of listed securities and turnover ratio result in an increase in gross domestic product. The implication of this is that the economy responded favourably to measures taken to increase market capitalization, volume of stock traded, value of stock traded, number of listed securities and turnover ratio in Nigeria Stock Exchange. However, it is recommended, that the Security and Exchange Commission (SEC) should formulate good and workable policies that will revive and improve the Nigerian capital market so that it will have breadth and depth and to make the Nigeria capital market efficient.
\end{abstract}

Published by IJRP.ORG. Selection and/or peer-review under responsibility of International Journal of Research Publications (IJRP.ORG)

Keywords: Capital market; Poverty Alleviation; GDP

\section{Introduction}

Finance is one of the most valuable and important assets of any nation for it can revive and direct an economy towards growth, if it is effectively put into use, hence, every government should be able to use its finance to develop and uplift its economy. The capital market is a market that is known for long term finance (Nzotta, 2015). Capital Market is a market where medium to long term finances are raised (Okereke-Onyuike, 2016). The capital market is a market that is highly sophisticated and well organized financial market, for those who need long term funds and it has the ability of directing the economy to the part of economic growth. The capital market deals on long-term funds (Osazee, 2016). The history of capital market in Nigeria can be traced 
to Mr. J. B. Lobynesion in 1959, when he was called upon by the government, to advice the government on the functions that the Central Bank in the financial market as well as the development of a sound, well organized, sophisticated and an efficient capital market, which has breadth and depth, the government later called upon Barback Committee to make salient and useful recommendations on having an efficient stock market, to be precise and concise the federal government of Nigeria implemented the recommendations of Barback committee and on the 15th of September 1960 the Lagos stock market was established as a formal capital market and in 1977 the Lagos stock market was renamed the Nigerian stock exchange (OkerekeOnyuike, 2016). The Nigerian stock exchange has two sections, the Primary market which is also called new issues market, it is a market that provide platform for the placement of new issues of securities in the market. The first time a company issues shares at the primary market is said to be an initial public offer (IPO) (Nzotta, 2015). Secondary market is the formal market for trading old stocks and shares, bonds or debentures and other long-term securities (Nzotta, 2015).

\subsection{Objectives of the Study}

The main objective of this study is to determine the influence of capital market operations on the Nigeria economic growth. Specific objectives are to:

i. Examine the relationship between Market Capitalization and Nigeria economic growth.

ii. Ascertain the relationship between Volume of stock traded and Nigeria economic growth.

iii. Determine the significant relationship between Value of stock traded and Nigeria economic growth.

iv. Examine the relationship between Number of listed securities and Nigeria economic growth.

v. Appraise the relationship between turnover ratio and Nigeria economic growth.

\subsection{Research Questions}

Based on the forgoing the questions of the study are:

i. What is the relationship between Market Capitalization and the Nigeria economic growth?

ii. Does Volume of stock traded have significant relationship with Nigeria economic growth?

iii. What is the relationship between Value of stock traded and the Nigeria economic growth?

iv. Is there any significant relationship between Number of listed securities and the Nigeria economic growth?

v. Is there any significant relationship between turnover ratio and Nigeria economic growth?

\subsection{Construction of references}

The following hypotheses have been formulated as guides to finding answers to the research questions. The hypotheses are stated in the null form. They include:

H01: Market Capitalization has no significant relationship with Nigeria economic growth.

H02: There is no significant relationship between Volume of stock traded and Nigeria economic growth.

H03: Value of stock traded has no significant relationship with Nigeria economic growth.

H04: There is no significant relationship between Number of listed securities and Nigeria economic growth.

H05: There is no significant relationship between Turnover ratio and Nigeria economic growth. 


\section{Literature Review}

\subsection{Capital Market}

The capital market is the life wire of any economy because it provides long term capital for government, corporate bodies and investors who need long term funds (Demirgüç-Kunt \& Levine, 2013). In a study done by Demirgüç-Kunt and Levine, from 2000 to 2011 using OLS the result reveals that capital market has the ability of boosting the economy.

Capital market is a market for long term loanable finance (Khan 2016) In a study done by Khan from 2000 to 2015 using OLS it shows that capital market play a huge role in economic growth. The Capital market provides opportunities, fund mobilization, Creation of liquidity, Mobilization of savings, It enhance Capital Formation, it enhance Risk diversification, It provides a place where the suppliers and users of long term funds for productive and investment purposes can meet (Nieuwerburgh, Buelens, \& Cuyvers, 2015). In a study done by Nieuwerburgh, Buelens and Cuyvers from 2002 to 2012 using cointegration shows that capital market provides capital for fund users thereby improving economic growth. The capital market is a market for long term financial securities such as bonds, stock, debenture among others (Hsu, 2014).

\subsection{Capital Market and Poverty Alleviation}

Chee (2014) opined that capital market promotes effective deposit mobilization, alleviate poverty and ensure allocation of funds to efficiently managed firms that offer high returns on capital. In a study done by Chee (2014) from 2000-2012 using co-integration, the result shows that capital market has the ability to reduce poverty. Financial market theory postulates that capital market enhance competition, reduces poverty, encourages international trade and specialization, enhances market efficiency and drives the process of economic growth of a country (Bekaert, 2010). Capital market has the ability to alleviate poverty because the capital market can be used as a tool to reduce poverty (Demirgüç-Kunt \& Levine, 2013). In a study done by Demirgüç-Kunt and Levine, from 1998 to 2012 using OLS the result shows that capital market has the capacity of reducing poverty in a nation. Khan (2016) said that capital market can reduce poverty in a country. In a study done by Khan from 2001 to 2014 using OLS it shows that capital market has the ability to reduce poverty. When poverty is reduced there will also be a reduction in crime in the society, poverty eradication has been a major problem in Nigeria, and successive government has tried to eradicate poverty using different programmes that has not yielded tangible result, hence, the need for an efficient capital market.

\subsection{Capital Market and Economic Growth}

Economic growth is an increase in the productive output of a country, when there is a constant and steady increase in productive output over a long period of time it will be termed growth, capital market has the ability to redirect the economy towards the part of growth (Levine \& Servos, 2014) In a study done by Levine \& Servos from 1999 to 2012 using co integration shows that capital market enhance economic growth. Economic growth refers to the process in which productive abilities and capacity of an economy increases over a given period of time causing an increment in the level of national income (Nieuwerburgh, Buelens, \& Cuyvers, 2015) in a study done by Nieuwerburgh, Buelens, \& Cuyvers from 2000 to 2014 using OLS shows that capital market has the ability to revive an economy. When there is economic growth it shows in the increase in income level, if there is an increment in the income level it is a sign of economic growth, hence, economic growth increase in income, when there is a sound capital market definitely there will be growth. Economic growth is the increase in the total capital stock of a country, hence, when there is an increment in 
the total capital stock of a country it is a sign of economic growth, capital market has the ability to gravitate the economy towards growth (Nzue, 2016). Capital market enhance economic growth (Jovanovic, 2013) In a study done by Jovanovic from 1999 to 2011 using co integration it shows that capital market can boost economic growth.

Jovanovic, (2013) examined the relationship between capital market and economic growth, he found out that there is a positive relationship between capital market and economic growth, using cointegration from 1999-2011. Levine and Servos, (2014) examines whether there is a strong relationship between capital market development and economic growth, co integration was used from 1999 to 2012, the result shows a positive relationship between capital market and economic growth. Demirgüç-Kunt and Levine (2013) looked at stock market size and economic growth, the study shows a relationship between stock market size and economic growth.

\section{Methodology}

The study adopts ex-post facto research design because the variable that we will be considering is historical in nature and the researcher does not have the ability or opportunity to vary the independent variables, it uses ordinary least square techniques to examine the nature of relationship between the variables. The aim of this study is to examine the impact of capital market operations on the Nigeria economy. Secondary data from Central Bank of Nigeria, NSE and NBS was used. The study covers the period of 27 years from 1990 to 2017. The population is the entire Nigerian capital market. For this type of study where data needed are fully sourced from the Central Bank of Nigeria, NSE and NBS. The Sample Size is the Nigerian capital market.

\subsection{Model Specification}

Gross domestic product (GDP) is expressed as a function of Market capitalization (MCAP), Value of stock traded (VST), Volume of stock traded (VOST), Number of listed securities (NLS) and Turnover ratio (TOR) for the period between 1990-2017.

The model for the study is specified as:

GDP $=$ Gross Domestic Product.

MCAP $=$ Market Capitalization.

VST $=$ Value of stock traded.

VOST = Volume of stock traded.

NLS $=$ Number of listed securities.

TOR $=$ Turnover ratio

ßo $\quad=$ Constant term

$\mu \quad=$ Error Term

GDP $=$ F (MCAP, VST, VOST, NLS, TOR)

This can be put in linear estimation form as above

$\mathrm{GDPt}=\beta \mathrm{o}+\beta 1 \mathrm{MCAPt}+\beta 2 \mathrm{VSTt}+\beta 3 \mathrm{VOSTt}+\beta 4 \mathrm{NLSt}+\beta 5 \mathrm{TOR} \mathrm{t}+\mu \mathrm{t}$

This can be put in econometrics estimation form as above

$\beta 1, \beta 2, \beta 3, \beta 4$ and $\beta 5$ are coefficient to be estimated 
DATA PRESENTATION AND ANALYSIS OF RESULT

Table 1: Gross domestic product, Market capitalization, Volume of stock traded, Value of stock traded Number of listed securities and Turnover ratio.

\begin{tabular}{|c|c|c|c|c|c|c|}
\hline YEAR & GDP & MCAP & VST & VOST & NLS & TOR \\
\hline 1990 & 260.64 & 16.30 & 5.7 & 43.9 & 110 & 1.01 \\
\hline 1991 & 324.01 & 23.10 & 5.6 & 42.0 & 120 & 1.22 \\
\hline 1992 & 549.81 & 31.20 & 6.9 & 32.7 & 134 & 1.34 \\
\hline 1993 & 695.99 & 47.50 & 9.1 & 48.3 & 122 & 1.41 \\
\hline 1994 & 911.07 & 66.30 & 7.7 & 58.9 & 144 & 1.50 \\
\hline 1995 & 1960.69 & 180.40 & 9.3 & 67.5 & 198 & 1.07 \\
\hline 1996 & 2740.46 & 285.80 & 4.8 & 65.1 & 197 & 2.47 \\
\hline 1997 & 2835.01 & 281.90 & 8.8 & 76.6 & 200 & 3.97 \\
\hline 1998 & 2765.67 & 262.60 & 9.7 & 85.2 & 215 & 5.91 \\
\hline 1999 & 3193.67 & 300.00 & 9.4 & 72.7 & 212 & 3.83 \\
\hline 2000 & 4842.19 & 472.30 & 7.8 & 90.2 & 265 & 4.11 \\
\hline 2001 & 5487.10 & 662.50 & 10.1 & 103.4 & 244 & 5.05 \\
\hline 2002 & 5454.20 & 764.90 & 10.8 & 100.8 & 264 & 6.86 \\
\hline 2003 & 7180.10 & 1359.30 & 13.3 & 120.4 & 265 & 8.09 \\
\hline 2004 & 8265.0 & 2112.50 & 19.2 & 225.8 & 277 & 10.59 \\
\hline 2005 & 7839.20 & 2900.06 & 26.7 & 262.9 & 288 & 8.78 \\
\hline 2006 & 18572.59 & 5120.90 & 36.5 & 470.3 & 288 & 10.96 \\
\hline 2007 & 206507311.7 & 13181.69 & 138.1 & 2100.0 & 309 & 20.45 \\
\hline 2008 & 24296329.2 & 9562.97 & 193.1 & 2400.0 & 299.0 & 34.79 \\
\hline 2009 & 24794238.0 & 7030.84 & 102.9 & 685.7 & 266.0 & 13.94 \\
\hline 2010 & 29205787.9 & 9918.21 & 107.5 & 688.3 & 264.0 & 10.10 \\
\hline 2011 & 39875863.8 & 10275.34 & 39.07 & 567.9 & 262 & 9.92 \\
\hline 2012 & 57854367.6 & 14800.94 & 198.9 & 756.8 & 272 & 9.00 \\
\hline 2013 & 67845678.1 & 19077.42 & 357.3 & 895.9 & 300.0 & 8.5 \\
\hline 2014 & 86795438.6 & 16875.10 & 458.5 & 988.7 & 299 & 8.18 \\
\hline 2015 & 65123445.2 & 17003.39 & 523.4 & 874.7 & 271 & 8.17 \\
\hline 2016 & 67245687.9 & 16185.73 & 617.3 & 976.1 & 249 & 5.36 \\
\hline 2017 & 69675434.8 & 18435.23 & 623.4 & 984.2 & 309 & 6.01 \\
\hline
\end{tabular}

Sources: Central bank of Nigeria, Nigeria stock exchange and National Bureau of Statistics 2017.

Table 2: OLS Estimation

\begin{tabular}{|l|l|l|l|}
\hline Variable & Coefficient & Std. Error & t-Statistic \\
\hline C & 34578404 & 17275921 & 2.001538 \\
\hline MCAP & 1432.120 & 1503.216 & $\mathbf{0 . 9 5 2 7 0 4}$ \\
\hline VOST & 149752.9 & 42936.99 & 3.487737 \\
\hline VST & 154784.2 & 21451.22 & 7.215637 \\
\hline NLS & 314099.3 & 100808.9 & 3.115790 \\
\hline TOR & 10462358 & 1688174. & 6.197440 \\
\hline R-squared & $\mathbf{0 . 8 8 4 9 1 6}$ & F-statistic & 32.29510 \\
\hline Adjusted R-squared & $\mathbf{0 . 8 5 7 5 1 5}$ & Prob(F-statistic) & $\mathbf{0 . 0 0 0 0 0 1}$ \\
\hline Durbin-Watson stat & 2.461497 & & \\
\hline
\end{tabular}

Source: E-views 9 
$\mathrm{C}$ is the intercept or the constant term, it measures the past and current changes that have taken place. It measures the past and current variation changes of the independent variables on the dependent variable. From our study, the result of the intercept appears with a positive result of 34578404 and a t ratio of 2.001538 the implication of this outcome or result is that above lunit change in the constant term exert over 345 unit change on GDP.

The MCAP shows a positive relationship with a value of 1432.120 with a t ratio of 0.952704 this shows that 1 unit change will exert over 14 unit change on GDP.

VOST is 149752.9 with a t statistics of 3.487737 this shows that 1 unit change in VOST exert over approximately 15 unit change on GDP. VST is 154784.2 with a $t$ ratio of 7.215637 this means that 1 unit change in VST will exert 15 unit change in GDP. NLS has a positive value of 314099.3 with t statistics of 3.115790 which shows that 1 unit change in NLS will exert 31 unit change on GDP. TOR is 10462358 with a $\mathrm{t}$ ratio of 6.197440 this means that 1 unit change in TOR will lead to 10 unit change in GDP.

R2 is a statistical tool for measuring goodness-of-fit among the variables of the model. From our study the value of R2 stands at 0.884916 which is $88 \%$ this indicate that all the changes in the independent variables put together was able to explain over $88 \%$ of the systematic variations in the dependent variables leaving over $12 \%$ unaccounted for this short fall could be attributed to other relevant variables that are not included in our model.

Adjusted R-squared: measures the goodness-of-fit among the variables of our model but after allowing for the degree of freedom. The adjusted R-squared is 0.857515 this means that all the independent variables in our model was able to explain approximately $86 \%$ of the systematic variations leaving $14 \%$ to be accounted for by the error term.

DW-statistics: this statistical tool establishes the presence or absence of autocorrelation. The DW-statistics is 2.461497 it shows the absence of autocorrelation.

F-Statistics: measures the overall significance of a study, from our result the value of our F-statistics is $32.29510(0.000001)$ this indicates that the study is significant at $1 \%$ level of significance, in other words the study is quiet significant to policy makers.

Table 3 Descriptive Statistics

\begin{tabular}{|l|c|c|c|c|c|c|}
\hline & GDP & MCAP & VOST & VST & NLS & TOR \\
\hline Mean & $\mathbf{2 4 6 1 5 4 8 2}$ & $\mathbf{5 5 1 1 . 0 8 1}$ & $\mathbf{4 7 7 . 8 0 7 4}$ & $\mathbf{1 0 8 . 7 9 5 2}$ & $\mathbf{2 3 4 . 5 9 2 6}$ & $\mathbf{7 . 6 5 1 1 1 1}$ \\
\hline Median & $\mathbf{7 1 8 0 . 1 0 0}$ & $\mathbf{1 3 5 9 . 3 0 0}$ & $\mathbf{1 2 0 . 4 0 0 0}$ & $\mathbf{1 3 . 3 0 0 0 0}$ & $\mathbf{2 6 4 . 0 0 0 0}$ & $\mathbf{6 . 8 6 0 0 0 0}$ \\
\hline Maximum & $\mathbf{2 . 0 7 E + 0 8}$ & $\mathbf{1 9 0 7 7 . 4 2}$ & $\mathbf{2 4 0 0 . 0 0 0}$ & $\mathbf{6 1 7 . 3 0 0 0}$ & $\mathbf{3 0 9 . 0 0 0 0}$ & $\mathbf{3 4 . 7 9 0 0 0}$ \\
\hline Minimum & $\mathbf{2 6 0 . 6 4 0 0}$ & $\mathbf{1 6 . 3 0 0 0 0}$ & $\mathbf{3 2 . 7 0 0 0 0}$ & $\mathbf{4 . 8 0 0 0 0 0}$ & $\mathbf{1 1 0 . 0 0 0 0}$ & $\mathbf{1 . 0 1 0 0 0 0}$ \\
\hline Std. Dev. & $\mathbf{4 5 3 7 5 6 5 7}$ & $\mathbf{6 6 7 9 . 4 1 6}$ & $\mathbf{6 1 2 . 8 6 4 4}$ & $\mathbf{1 7 5 . 0 1 5 9}$ & $\mathbf{6 1 . 5 3 5 6 4}$ & $\mathbf{7 . 0 8 1 3 0 6}$ \\
\hline Skewness & $\mathbf{2 . 6 2 0 2 1 2}$ & $\mathbf{0 . 8 1 4 7 1 6}$ & $\mathbf{1 . 8 4 4 3 5 4}$ & $\mathbf{1 . 7 9 9 2 2 9}$ & $\mathbf{- 0 . 8 2 7 5 7 2}$ & $\mathbf{2 . 2 6 6 1 4 7}$ \\
\hline Kurtosis & $\mathbf{1 0 . 6 0 1 6 2}$ & $\mathbf{2 . 0 7 7 3 2 1}$ & $\mathbf{5 . 9 9 2 4 0 1}$ & $\mathbf{4 . 9 7 5 5 7 1}$ & $\mathbf{2 . 3 9 8 0 2 1}$ & $\mathbf{9 . 2 5 3 2 4 2}$ \\
\hline Jarque-Bera & $\mathbf{9 5 . 9 0 2 5 1}$ & $\mathbf{3 . 9 4 4 6 8 6}$ & $\mathbf{2 5 . 3 8 1 1 5}$ & $\mathbf{1 8 . 9 5 8 2 5}$ & $\mathbf{3 . 4 8 9 6 1 7}$ & $\mathbf{6 7 . 1 0 0 3 0}$ \\
\hline Probability & $\mathbf{0 . 0 0 0 0 0 0}$ & $\mathbf{0 . 1 3 9 1 3 0}$ & $\mathbf{0 . 0 0 0 0 0 3}$ & $\mathbf{0 . 0 0 0 0 7 6}$ & $\mathbf{0 . 1 7 4 6 7 8}$ & $\mathbf{0 . 0 0 0 0 0 0}$ \\
\hline Sum & $\mathbf{6 . 6 5 E + 0 8}$ & $\mathbf{1 4 8 7 9 9 . 2}$ & $\mathbf{1 2 9 0 0 . 8 0}$ & $\mathbf{2 9 3 7 . 4 7 0}$ & $\mathbf{6 3 3 4 . 0 0 0}$ & $\mathbf{2 0 6 . 5 8 0 0}$ \\
\hline Sum Sq. Dev. & $\mathbf{5 . 3 5 E}+16$ & $\mathbf{1 . 1 6 E}+09$ & $\mathbf{9 7 6 5 6 7 3 .}$ & $\mathbf{7 9 6 3 9 4 . 5}$ & $\mathbf{9 8 4 5 2 . 5 2}$ & $\mathbf{1 3 0 3 . 7 6 7}$ \\
\hline Observations & $\mathbf{2 7}$ & $\mathbf{2 7}$ & $\mathbf{2 7}$ & $\mathbf{2 7}$ & $\mathbf{2 7}$ & $\mathbf{2 7}$ \\
\hline
\end{tabular}

Source: E-view 9

The descriptive statistics shows the mean of all the variables considered, GDP has a mean of 24615482 the mean represents the average with the GDP mean of 24615482 this shows that the result is good because the dependent variable has a positive and a high mean, MCAP has a mean of 5511.081 this also shows that the mean of the MCAP is good because it has a positive and a high value, VOST has a mean of 477.8074 this is 
also a good value, VST has a mean of 108.7952 this is a positive value and it is good, NLS has a value of 234.5926 this mean value is also significant to our study, TOR has a mean of 7.651111 this is also a positive value and it is statistically significant to our study because it shows the relationship among the variables with respect to their mean. The median of the variables shows that GDP has 7180.100 this is a positive and a good value this is statistically significant to our study, MCAP has a value of 1359.300 this reveals that the value of MCAP is statistically significant to the study, VOST has a median of 120.4000 this value is good and significant to the study, VST has a value of 13.30000 this value shows that the median is good, NLS has a value of 264.0000 and TOR has a value of 6.860000 this is statistically significant to the study. The JarqueBera shows the variables that depart from normality, from the result GDP has a value of 95.90251, MCAP 3.944686, VOST 25.38115, VST 18.95825, NLS 3.489617 and TOR 67.10030 MCAP and NLS departed from normality.

Table 4: UNIT ROOT TEST FOR VARIABLES AT LEVEL

AT FIRST DIFFERENCING

\begin{tabular}{|l|l|l|l|l|l|l|l|}
\hline $\begin{array}{l}\text { Variables } \\
\text { At level }\end{array}$ & $\begin{array}{l}\text { Computed } \\
\text { ADF } \\
\text { statistics }\end{array}$ & $\begin{array}{l}\text { 95\% } \\
\text { critical } \\
\text { ADF } \\
\text { statistics }\end{array}$ & Remark & $\begin{array}{l}\text { Variables } \\
\text { At first } \\
\text { Difference }\end{array}$ & $\begin{array}{l}\text { Computed } \\
\text { ADF } \\
\text { statistics }\end{array}$ & $\begin{array}{l}\text { 95\% critical } \\
\text { ADF } \\
\text { statistics }\end{array}$ & Remark \\
\hline GDP & $\mathbf{- 8 . 9 9 3 4 6 1}$ & $\mathbf{- 1 . 9 5 4 4 1 4}$ & Stat & DRGDP & $\mathbf{- 8 . 3 1 7 9 8 3}$ & $\mathbf{- 1 . 9 5 5 0 2 0}$ & Stat \\
\hline MCAP & $\mathbf{0 . 5 9 8 4 4 0}$ & $\mathbf{- 1 . 9 5 4 4 1 4}$ & Non-Stat & DMCAP & $\mathbf{- 4 . 6 9 6 6 0 7}$ & $\mathbf{- 1 . 9 5 5 0 2 0}$ & Stat \\
\hline VOST & $\mathbf{4 . 2 6 7 2 3 4}$ & $\mathbf{- 1 . 9 5 4 4 1 4}$ & Stat & DVOST & $\mathbf{- 4 . 7 3 1 8 3 7}$ & $\mathbf{- 1 . 9 5 5 0 2 0}$ & Stat \\
\hline VST & $\mathbf{- 1 . 3 5 4 6 0 5}$ & $\mathbf{- 1 . 9 5 4 4 1 4}$ & Non-Stat & DVST & $\mathbf{- 5 . 0 6 8 5 7 8}$ & $\mathbf{- 1 . 9 5 5 0 2 0}$ & Stat \\
\hline NLS & $\mathbf{- 0 . 7 1 8 4 2 6}$ & $\mathbf{- 1 . 9 5 4 4 1 4}$ & Non-Stat & DNLS & $\mathbf{- 4 . 6 5 9 7 2 0}$ & $\mathbf{- 1 . 9 5 5 0 2 0}$ & Stat \\
\hline TOR & $\mathbf{- 1 . 3 0 8 7 7 7}$ & $\mathbf{- 1 . 9 5 4 4 1 4}$ & Non-Stat & DTOR & $\mathbf{- 5 . 2 7 9 3 9 7}$ & $\mathbf{- 1 . 9 5 5 0 2 0}$ & Stat \\
\hline
\end{tabular}

Source: E view 9

The unit root test for stationarity. The unit root test shows that GDP and VOST were significant at levels while MCAP, VST, NLS and TOR were stationary after the first difference. From the result GDP shows a figure of -8.993461 and the critical value is -1.954414 , the DGDP is -8.317983 , the critical value is 1.955020 , this value is good and it reveals that GDP is stationary at level, MCAP shows ADF of 0.598440 , critical value of -1.954414 show non-stationarity at level, after the first differencing DMCAP became stationary at -4.696607 and critical value of -1.955020 . VOST show 4.267234 , with a critical value of 1.954414 this means that the variable is stationary at level. DVOST is -4.731837 , the critical value is 1.955020 this shows that the variable is stationary at level. VST is -1.354605 , critical value of -1.954414 showing the variable is non-stationary at level, but after the first differencing, DVST became stationary with 5.068578 and critical value of -1.955020 , NLS is -0.718426 , critical value of -1.954414 , showing nonstationarity, DNLS is -1.954414 , critical value of -4.659720 showing stationarity after first differencing. TOR is -1.308777 , critical value of -1.954414 showing non-stationarity. DTOR is -5.279397 , critical value of 1.955020 meaning that the variable is stationary after the first differencing. 
Table 5

Co-integration Test

Unrestricted Co-integration Rank Test (Trace)

\begin{tabular}{|l|l|l|l|l|l|}
\hline Hypothesized No. of CE(s) & Eigen value & $\begin{array}{l}\text { Trace } \\
\text { Statistic }\end{array}$ & $\mathbf{5 \%}$ Critical Value & Prob.** & \\
\hline None * & $\mathbf{0 . 9 9 1 3 3 2}$ & $\mathbf{2 4 3 . 0 6 3 4}$ & $\mathbf{9 5 . 7 5 3 6 6}$ & $\mathbf{0 . 0 0 0 0}$ & \\
\hline At most 1 * & $\mathbf{0 . 9 9 1 3 3 2}$ & $\mathbf{1 2 4 . 3 6 0 0}$ & $\mathbf{6 9 . 8 1 8 8 9}$ & $\mathbf{0 . 0 0 0 0}$ & \\
\hline At most 2 * & $\mathbf{0 . 7 4 3 1 5 6}$ & $\mathbf{7 4 . 7 5 4 2 5}$ & $\mathbf{4 7 . 8 5 6 1 3}$ & $\mathbf{0 . 0 0 0 0}$ & \\
\hline At most 3 * & $\mathbf{0 . 6 3 6 9 2 4}$ & $\mathbf{4 0 . 7 7 2 0 9}$ & $\mathbf{2 9 . 7 9 7 0 7}$ & $\mathbf{0 . 0 0 1 9}$ & \\
\hline At most 4 & $\mathbf{0 . 3 1 7 5 2 2}$ & $\mathbf{1 5 . 4 4 3 4 9}$ & $\mathbf{1 5 . 4 9 4 7 1}$ & $\mathbf{0 . 0 5 0 9}$ & \\
\hline At most 5 * & $\mathbf{0 . 2 0 9 9 9 4}$ & $\mathbf{5 . 8 9 2 8 6 4}$ & $\mathbf{3 . 8 4 1 4 6 6}$ & $\mathbf{0 . 0 1 5 2}$ & \\
\hline
\end{tabular}

Source: E-View 9

The co-integration test shows four (4) co-integrating equation as show in the trace test at $1 \%$ level of significance, the trace value shows a positive value of 243.0634 this is a good value, the co-integration test also reveals $124.3600,74,75425,40.77209,15.44349,3.841466$ these values are all positive values meaning that there is a positive relationship among the co-integrating variables, the eign value shows 0.991332 , $0.991332,0.743156,0.636924,0.317522$ and 0.209994 , the critical value shows $95.75366,69.81889$, $47.85613,29.79707,15.49471$ and 3.841466 and there are four co-integrating equation, this means that there is a long run relationship among the variables.

Table $6 \quad$ Error Correction Model

\begin{tabular}{|c|r|r|r|r|}
\hline VARIABLES & COEFFICIENT & STD.ERROR & T-STATISTIC & PROB. \\
\hline C & $\mathbf{7 9 4 9 8 1 . 5}$ & $\mathbf{3 7 1 8 9 4 9 .}$ & $\mathbf{0 . 2 1 3 7 6 5}$ & $\mathbf{0 . 8 3 3 0}$ \\
\hline DMCAP & $\mathbf{3 5 3 2 . 3 9 4}$ & $\mathbf{2 5 8 2 . 0 3 0}$ & $\mathbf{1 . 3 6 8 0 6 9}$ & $\mathbf{0 . 1 8 7 3}$ \\
\hline DVOST & $\mathbf{1 7 9 1 1 5 . 0}$ & $\mathbf{7 0 5 2 8 . 8 9}$ & $\mathbf{2 . 5 3 9 5 9 8}$ & $\mathbf{0 . 0 2 0 0}$ \\
\hline DVST & $\mathbf{1 4 8 0 2 8 . 0}$ & $\mathbf{2 1 7 3 8 . 1 6}$ & $\mathbf{6 . 8 0 9 5 9 1}$ & $\mathbf{0 . 0 0 0 0}$ \\
\hline DNLS & $\mathbf{3 6 1 5 5 0 . 6}$ & $\mathbf{1 8 1 4 0 7 . 8}$ & $\mathbf{1 . 9 9 3 0 2 7}$ & $\mathbf{0 . 0 6 0 8}$ \\
\hline DTOR & $\mathbf{1 0 9 1 1 9 2 9}$ & $\mathbf{1 4 5 5 2 5 6 .}$ & $\mathbf{7 . 4 9 8 2 8 7}$ & $\mathbf{0 . 0 0 0 0}$ \\
\hline ECM & $\mathbf{1 . 1 7 3 9 7 1}$ & $\mathbf{0 . 2 3 5 2 7 9}$ & $\mathbf{4 . 9 8 9 6 8 8}$ & $\mathbf{0 . 0 0 0 1}$ \\
\hline R-squared & $\mathbf{0 . 9 3 5 8 4 9}$ & F-statistic & $\mathbf{4 6 . 1 9 5 7 7}$ & \\
\hline $\begin{array}{l}\text { Adjusted R- } \\
\text { squared }\end{array}$ & $\mathbf{0 . 9 1 5 5 9 0}$ & Prob(F-statistic) & $\mathbf{0 . 0 0 0 0 0 1}$ & \\
\hline $\begin{array}{l}\text { Durbin-Watson } \\
\text { stat }\end{array}$ & $\mathbf{2 . 7 5 5 8 2 1}$ & & & \\
\hline
\end{tabular}

Source: E-views 9

$\mathrm{C}$ is the intercept or the constant term, it measures the past and current changes that have taken place. It measures the past and current variation changes of the independent variables on the dependent variable. From our study the result of the intercept appears with a positive result of 794981.5 and a $t$ ratio of 0.213765 the implication of this outcome or result is that above lunit change in the constant term exert over approximately 795 unit change on DGDP.

The DMCAP shows a positive relationship with a value of 3532.394 with a t ratio of 1.368069 this shows that 1 unit change will exerted over 35 unit change on DGDP.

DVOST is 179115.0 with a $t$ statistics of 2.539598 this show that 1 unit change in DVOST exert over approximately 18 unit change on DGDP. DVST is 148028.0 with a t ratio of 6.809591 this means that 1 unit change in DVST will exert approximately 15 unit change in GDP. DNLS has a positive value of 361550.6 
with $t$ statistics of 7.498287 which shows that 1 unit change in DNLS will exert 36 unit change on DGDP. DTOR is 10911929 with a $t$ ratio of 7.498287 this means that 1 unit change in DTOR will lead to approximately 11 unit change in DGDP.

R2 is a statistical tool for measuring goodness-of-fit among the variables of the model. Form our study the value of R2 stands at 0.935849 which is approximately $94 \%$ this indicate that all the changes in the independent variables put together was able to explain over $94 \%$ of the systematic variations in the dependent variables leaving over $6 \%$ unaccounted for this short fall could be attributed to other relevant variables that are not included in our model.

Adjusted R-squared: measures the goodness-of -fit among the variables of our model but after allowing for the degree of freedom. The adjusted R-squared is 0.915590 this means that all the independent variables in our model was able to explain approximately $92 \%$ of the systematic variations leaving $8 \%$ to be accounted for by the error term.

DW-statistics: this statistical tool establishes the presence or absence of autocorrelation. The DW-statistics is 2.755821 it shows the absence of autocorrelation.

F-Statistics: measures the overall significance of a study, from our result the value of our F-statistics is 46.19577 (0.000001) this indicates that the study is significant at $1 \%$ level of significance, in other words the study is quiet significant to the stack holders.

\section{Summary of Findings}

The study examined the influence of capital market on the Nigeria economic growth. between 1990 to 2017. The findings of the study reveal the following:

(i) The regression result confirms that there exist positive relationship between the capital market and economic growth. From our study the result of the intercept appears with a positive result of 794981.5 the implication of this outcome or result is that above lunit change in the constant term exert over approximately 795 unit change on DGDP. DMCAP shows a positive relationship with a value of 3532.394 this shows that 1 unit change will exerted over 35 unit change on DGDP. DVOST is 179115.0 this show that 1 unit change in DVOST exert over approximately 18 unit change on DGDP. DVST is 148028.0 this means that 1 unit change in DVST will exert approximately 15 unit change in GDP. DNLS has a positive value of 361550.6 with which shows that 1 unit change in DNLS will exert 36 unit change on DGDP. DTOR is 10911929 with this means that 1 unit change in DTOR will lead to approximately 11 unit change in DGDP. The relationship is statistically significance at 5\% level of significance. This is in essence means that the influence of the capital market on economic growth is strong and significant.

(ii) Another major outcome of the study is that a unit increase in MCAP, VOST, DVST, NLS and TOR result in an increase in GDP. The implication of this is that the economy responds favourably to measures taken to increase MCAP, VOST, DVST, NLS and TOR in Nigeria Stock Exchange.

(iii) The positive result of MCAP, VOST, DVST, NLS and TOR implies that funds raised by the industries and governments in the capital market are spent on productive sector which enhance economic growth.

(iv) The result of VOST, DVST and NLS in the capital market means that capital market serve as a source of finance for the government and industries.

(v) R2 is a statistical tool for measuring goodness-of-fit among the variables of the model. From our study the value of R2 stands at $94 \%$ and adjusted R-squared is $92 \%$. DW-statistics this statistical tool establishes the presence or absence of autocorrelation. DW-statistics is 2.755821 . This show that there is a positive relationship between capital market operations and the Nigeria economic growth. 
It is also revealed from the study that capital market operations have the capacity to influence the entire economic growth of Nigeria if it is properly organized, the capital market helps to mobilize funds from where there is surplus to where there is deficit, Mobilization of savings, creation of liquidity.

\section{Conclusion}

The study reveals that the capital market influence economic growth through market capitalization, volume of stock traded, value of stock traded, number of listed securities and turnover rate. As it was observed market capitalization, volume of stock traded, value of stock traded, number of listed securities and turnover rate are important capital market variables that are capable of influencing economic growth. Hence the capital market influence economic growth therefore the government, foreign and private sector is to invest in it. The market capitalization, volume of stock traded, value of stock traded, number of listed securities and turnover rate have a significant influence on the GDP.

(i) Market Capitalization have a positive influence on the Nigeria economic growth.

(ii) volume of stock traded shows a positive value meaning it have a significant relationship with Nigeria economic growth.

(iii) value of stock traded reveals a positive relationship with Nigeria economic growth.

(iv) number of listed securities also shows a significant relationship with economic growth.

(v) turnover rate also reveals positive relationship with Nigeria economic growth.

\section{Recommendations}

In order for the Nigeria capital market to influence Nigeria economic growth and development, the following recommendations are suggested.

(i) Foreign investors should be encourage to participate in the capital market.

(ii) There should be financial openness in the Nigeria capital market, as to restore confidence to the capital market by regulatory bodies/authorities such as SEC and CBN.

(iii) There should be increase in the number of listed securities and in the volume and value of transactions in the Nigeria capital market, i.e there should be breadth and depth in the Nigeria capital market.

(iv) There should be a flexible tax system and tax rationalization in the capital market as to encourage quotation of financial instruments.

(v) To increase the value of stock traded, rate of turnover and volume of stock traded in the Nigerian capital market, there is need for availability of more financial instruments such as bonds, options, derivatives, stocks, convertibles, swaps, future and shares in the capital market.

it is also recommended that the Security and Exchange Commission (SEC) should formulate good and workable policies that will revive and improve the Nigerian capital market so that it will be efficient.

\section{References}

Bekaert, G. (2010), “Equity Market Liberalization in Emerging Markets,” Journal of Financial Research.

Central Bank of Nigeria (2016), "Nigeria: Major Economic, Financial and Banking Indicators" Available at: http://www.cenbank.org/documents/Statbulletin.asp.

Chee (2014). Appraisal of stock Market Efficiency on Economic Growth.

Demirgue Kunt, A. \& Levine, R. (2013), "Stock Market Development and Financial Intermediaries: Stylized Facts", The World bank Economic Review, Vol. 10. 
Hsu, C. (2014). The role of financial development in economic growth: The experiences of Taiwan, Korea \& Japan. Journal of Asian economics.

Jovanovic, B. (2013), "Financial Development, Growth, and the Distribution of Income”, The Journal of Political Economy, Vol. 98, pp. 1076-1107.

Khan M.(2016). A quantitative re-assessment of finance growth nexus", Evidence from a multivariate VAR. Journal of development economics.

Levine, R. \& Servos, S. (2014). Stock Market Development and Long-Run Growth. Policy Research Working Paper, No. 1582. The World Bank, March.

National Bureau of Statistics. (2016).

Nieuwerburgh, S., Buelens, F. \& Cuyvers, L. (2015).Stock market development and economic growth in Belgium, Explorations in Economic History, Global Finance Journals. 43, 13-38.

Nigeria Stock Exchange (2016).

Nzotta, S.M.(2015) Money, banking and finance, osprey publishers.

Nzue, F. (2016), “Stock Market Development and Economic Growth: Evidence from Cote D'Ivore”, Africa Development Review.

Okereke-Onyuki, O.(2016). Stock market development and private investment growth in Nigeria, Journal of development in Africa, 11(11), 20-35.

Osaze, E. B. (2016) 'The Historical Evolution of the Nigerian Capital Market'. 